\title{
Tecitura do vínculo em saúde na situação familiar de adoecimento crônico*
}

\author{
Juliana de Lima Soares ${ }^{(a)}$ \\ Laura Filomena Santos de Araújo(b) \\ Roseney Bellato(c) \\ Elen Petean ${ }^{(\mathrm{d})}$
}

Soares JL, Araújo LFS, Bellato R, Petean E. Weaving of the health bond on the family situation of chronic illness. Interface (Botucatu). 2016; 20(59):929-40.

This paper intended to understand the weaving of the bond in the relationship among practitioner, diseased person and family on chronic illness situations. It was a qualitative study performed from a consultation with the database collection of matrix research, retrieving three situations of chronic illnesses. The relationship maintained by Ms. Mocinha with her physician was characterized by a unidirectional affective bond. In the Soneto's family, the relationship between the adolescents and the physician was underpinned by reciprocity and professional accountability, constituting a bidirectional bond. In the Andre's family, the medical follow-up had a tie of friendship, contributing to the proactive performance of the professional throughout care. The studied persons/ families did not establish bond with the Basic Health Units, despite living in areas covered by the Family Health Strategy.

Keywords: Family. Professional-family relationships. Chronic disease.
Objetivamos compreender a tecitura do vínculo na relação entre profissional, pessoa adoecida e família em situação crônica de adoecimento. Trata-se de um estudo qualitativo realizado a partir de consulta ao acervo do banco de dados da pesquisa matricial, resgatando três situações de adoecimento crônico. A relação mantida por Dona Mocinha com seu médico se caracterizou pelo vínculo afetivo unidirecional. Na família Soneto, a relação entre os adolescentes e o médico estava embasada na reciprocidade e responsabilização profissional, constituindo um vínculo bidirecional. Na família de André, o acompanhamento médico contava com um laço de amizade, contribuindo para a atuação proativa do profissional no cuidado. As pessoas/famílias estudadas não estabeleceram vínculo com as Unidades Básicas de Saúde, apesar de viverem em áreas cobertas pela Estratégia Saúde da Família.

Palavras-chave: Família. Relações profissional-família. Doença crônica.

\footnotetext{
Estudo desenvolvido no âmbito da Pesquisa Matricial "As instituições de saúde e do poder judiciário como mediadores na efetivação do direito pátrio em saúde: análise de itinerários terapêuticos de pessoas/ famílias no SUS/MT", financiada pelo Edital de Apoio à Pesquisa da UFMT - Campus Sede/ Edição 001 $(a, b, c, d)$ Faculdade de Enfermagem, Universidade Federal de Mato Grosso. Avenida

Fernando Correa da Costa, n 2.367, Boa Esperança. Cuiabá, MT,

Brasil.juhsoaress@ yahoo.com.br (bolsista da Fundação de Amparo à Pesquisa do Estado de Mato Grosso (FAPEMAT); laurafil1@ yahoo.com.br; roseneybellato@ gmail.com; elenpetean@ yahoo.com.br (bolsista Capes)
} 


\section{Introdução}

Este estudo aborda a tecitura do vínculo entre o profissional de saúde e a pessoa/família que experiencia uma situação de adoecimento crônico. Tal situação se configura como um modo próprio de vivenciar a doença; e os eventos enfrentados pela pessoa adoecida e família produzem imbricações e entrelaçamentos, afetando-Ihes nas diversas dimensões da vida, conformando seus modos de viver, o que exige rearranjos para a reordenação do cotidiano na presença do adoecimento1.

A situação crônica de adoecimento requer atenção profissional contínua, que deve ser prestada longitudinalmente, o que implica a existência de um aporte regular de cuidados, por vezes, permanentes, num ambiente em que prevaleça a relação de confiança mútua entre profissionais e pessoas adoecidas ${ }^{2}$. Ainda, salientamos que tal atenção deva estar centrada nas pessoas e suas famílias e, por certo, preceitua a construção de uma relação entre profissional e família baseada em compromisso, ética e corresponsabilidade ${ }^{3}$.

Destarte, o vínculo refere-se à construção de relações de afetividade e confiança entre profissional de saúde e pessoa/família, permitindo o aprofundamento do processo de responsabilização pela saúde construído ao longo do tempo, além de carregar, em si, um potencial terapêutico ${ }^{4}$.

Ademais dos aspectos afetivos, consideramos que a tecitura do vínculo contribui para uma assistência mais efetiva, viabilizada pela responsabilização do profissional na produção de cuidados, de modo que ele tenha permanência na vida das pessoas, sendo elemento fundamental no cuidado em saúde.

Concordamos que a tecitura do vínculo deve ser de iniciativa do profissional de saúde para com as pessoas sob seus cuidados, fato que proporciona acolhimento e resposta às suas necessidades ${ }^{5}$. Assim, podemos considerar que o vínculo é efetivo quando se caracteriza pela longitudinalidade e efetividade no cuidado, sendo o profissional capaz de apreender as necessidades de saúde da pessoa cuidada e família, responsabilizando-se por responder àquelas que estejam sob suas possibilidades profissionais ${ }^{5}$.

O interesse por investigar o vínculo em saúde vem de estudo anterior ${ }^{5}$, baseado na trajetória de busca pelo cuidado de uma idosa com múltiplos agravos crônicos, que nos evidenciou a tecitura do vínculo afetivo unidirecional dessa pessoa com o profissional médico, visto que a iniciativa de busca e manutenção sempre a ela cabia. Esta relação de cunho vinculativo de caráter unidirecional, por afetar, de forma importante, a conformação da trajetória da família, nos fez pressupor que o vínculo tecido, em outro sentido, possuiria maior potencial de efetividade para o cuidado na situação crônica de adoecimento. É essa outra direcionalidade do vínculo - do profissional para a pessoa adoecida e sua família - que estamos nomeando de "vínculo em saúde", responsabilizando-o, portanto, como polo desencadeador e mantenedor da relação vinculante.

Este estudo poderá oferecer subsídios para uma discussão mais aprofundada dos elementos contribuidores na tecitura do vínculo em saúde, de modo a possibilitar maior efetividade da assistência prestada em todos os níveis de atenção. Assim, objetivamos compreender a tecitura do vínculo na relação entre profissional, pessoa adoecida e sua família na situação crônica de adoecimento.

\section{Metodologia}

Estudo de abordagem compreensiva, que nos permitiu apreender os diferentes significados atribuídos pelas pessoas aos processos que estão vivendo ${ }^{6}$, neste caso, a situação crônica de adoecimento, da qual depreendemos elementos imbricados na tecitura do vínculo. Foi realizado por meio de consulta a um Banco de Dados em Pesquisa Qualitativa (BDPQ) ${ }^{7}$, que se constitui em uma coleção de dados e informações recolhidas por diferentes pesquisadores sobre experiências de cuidado e adoecimento, sendo o seu conteúdo composto por histórias narradas por pessoas e suas famílias, compiladas em diários de pesquisa.

À época da consulta, o BDPQ continha 13 experiências familiares de cuidado e adoecimento, sendo de nosso interesse a compreensão da tecitura do vínculo em saúde a partir da perspectiva privilegiada das pessoas e suas famílias. Assim, este estudo se reporta aos critérios de inclusão da pesquisa matricial: a) ser usuária do Sistema Único de Saúde (SUS) em algum momento de sua experiência de adoecimento; 
b) ter recorrido a uma instância jurídica por meio de demanda judicial para requerer serviços e/ou insumos em saúde; c) ser residente no Estado de Mato Grosso.

Para a eleição das famílias a partir do BDPQ, empregamos o critério da presença de relações mais intensas entre profissionais de saúde e a pessoa adoecida/família, elegendo três experiências de adoecimento e cuidado: a) família de André, composta por ele, que vivenciou a experiência de adoecimento crônico implicado pelo câncer colorretal, sua esposa Gabi, seus três irmãos e dois filhos que participavam do cuidado. Os encontros com tal família foram de abril a junho/2010; b) família Soneto, que vivencia o adoecimento de dois adolescentes, Cecília e Olavo, de 13 e 14 anos, respectivamente, acometidos por anemia falciforme, e seus pais: Assis e Clarice. Os encontros com tal família foram de dezembro/2010 a outubro/2011; c) família de Dona Mocinha, composta pela idosa de 79 anos, que vivencia diversos agravos crônicos simultaneamente, sua filha Ana e seu genro Carlos, presentes em seu cotidiano de cuidados. Os encontros com eles foram de fevereiro a agosto/2011.

As três famílias residiam em Mato Grosso, sendo que a família de André vivia em uma cidade interiorana, e as demais na capital Cuiabá. Desse modo, os encontros com a família Soneto e de Dona Mocinha ocorreram em suas respectivas casas. O primeiro e segundo encontros com André ocorreram em um serviço público de saúde da capital, onde ele realizava tratamento quimioterápico; os encontros subsequentes aconteceram em sua cidade de residência.

$\mathrm{Na}$ recolha original destas experiências, foi empregada a abordagem metodológica da História de Vida operacionalizada pela Entrevista em Profundidade e Observação 7 . O trabalho de campo foi realizado por diferentes pesquisadores da pesquisa matricial, e a primeira autora deste estudo compôs a equipe que abordou a história da família de Dona Mocinha.

O corpus empírico se constituiu pelo Diário de Pesquisa das três experiências familiares, o que resultou num total de 543 páginas digitadas em arquivo Microsoft Word Document (docx), em fonte Times New Roman, tamanho 12 e espaçamento 1,5 entre linhas.

Para compreensão desse material, privilegiamos a leitura atenta e detalhada das narrativas de cada família, buscando por elementos e acontecimentos que expressavam a maneira pela qual se estabelecia a relação entre profissionais de saúde e família.

Inicialmente, destacamos, por meio de cores diferenciadas, os trechos narrativos que denotavam a conformação da relação com o profissional ou serviço de saúde e, posteriormente, os separamos do todo da entrevista, analisando-os um a um. Em seguida, discriminamos, em cada experiência familiar, os elementos que potencializavam ou dificultavam a tecitura e o fortalecimento do vínculo em saúde. A partir da identificação desses elementos, construímos um diagrama sintetizador representando os principais elementos intrínsecos à tecitura do vínculo nas experiências sobre as quais nos debruçamos.

A finalidade de um diagrama é usar os recursos visuais, linhas, formas, palavras, símbolos, setas, pontos ou planos que podem representar relacionamentos e propriedades de uma determinada estrutura $^{8}$. Assim, o diagrama possibilitou a demonstração ilustrativa dos elementos constitutivos do vínculo, bem como o contínuo das relações no tempo.

Os preceitos éticos de pesquisa com seres humanos foram respeitados, sendo a pesquisa matricial à qual este estudo se vincula aprovada pelo Comitê de Ética em Pesquisa. Os participantes assinaram o Termo de Consentimento Livre e Esclarecido, no qual estava prevista a composição do Banco de Dados e a possibilidade de consulta a seu acervo para o desenvolvimento de outros estudos. Também atribuímos nomes fictícios aos participantes deste estudo e profissionais/instituições de saúde citadas, buscando preservar seu anonimato.

\section{Resultados e discussão}

Partindo da ideia de vínculo como um importante constructo a ser encarnado pelo campo saúde, consideramos que a relação entre o profissional e as pessoas que necessitam de cuidados deve proporcionar meios para a sua tecitura. Assim, para apresentar, imageticamente, e discutir os elementos intrínsecos à constituição de uma relação pautada no vínculo em saúde, apreendidos nas experiências aqui interpretadas, construímos um diagrama (Figura 1). 


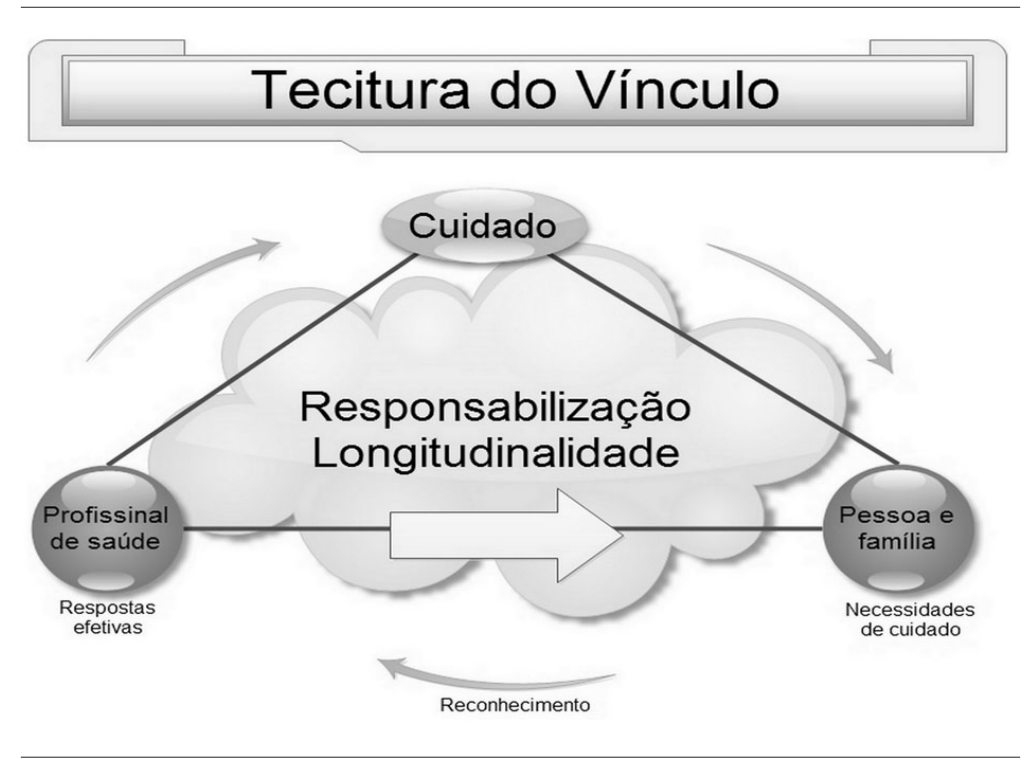

Figura 1. Diagrama representativo dos elementos intrínsecos à tecitura do vínculo na relação entre profissional, pessoa adoecida e família.

A tecitura do vínculo em saúde se constitui num movimento de relações que envolvem respostas efetivas do profissional de saúde para as necessidades de cuidado trazidas pelas pessoas ao longo do tempo, de maneira que elas possam reconhecer tais respostas como resolutivas, motivando-as a se vincularem ao profissional (Figura 1). Esse reconhecimento se torna viável quando o profissional e os serviços de saúde são capazes de estabelecer relações pautadas em elementos que potencializam o vínculo. Assim, com base nas experiências familiares, evidenciamos a responsabilização e a longitudinalidade como elementos indispensáveis à tecitura do vínculo, por contribuírem para o fortalecimento das relações.

$\mathrm{Na}$ experiência da família Soneto, percebemos a postura proativa do médico que acompanha os adolescentes no Centro de Hematologia Estadual há mais de dez anos. Tal postura contribuiu para a tecitura do vínculo em diversos momentos ao longo do adoecimento, dentre eles, salientamos o episódio em que o profissional se mostrou disponível para atender às necessidades dos adolescentes, mesmo estando afastado de suas atribuições, em período de férias, como ocorreu quando Cecília, filha de Clarice, sofreu um acidente vascular encefálico (AVE):

"Aí pegamos ela e viemos pro [nomeia o Hospital Público de Urgência e Emergência]. Quando chegamos, o médico não aceitava o diagnóstico. Ele falava que tinha que esperar o neuro, porque era uma paralisia facial que ela tava tendo, aí falei: 'Doutor, mas a minha filha tem anemia falciforme e ela pode tá tendo um AVC' [referindo-se ao AVE]. E ele falava: 'Não, anemia falciforme não dá AVC, anemia falciforme dá dor'. Aí eu falava: 'Doutor, não faz isso! Minha filha tá tendo um AVC e ela precisa ser transfundida com urgência'. [...] Fomos e ligamos pro médico [refere-se ao médico que acompanhava seus filhos há 10 anos], aí ele pediu que queria falar com o médico, que realmente ela tava tendo um AVC e precisava ser transfundida com urgência [...] Porque o médico não aceitava o parecer, aí o médico dela foi e pediu que ele queria falar com a assistente social e esclarecer o que tava acontecendo [...] Falou que ela era paciente dele, ele era o pediatra e hematologista que acompanhava ela, que cuidava dela e, se o colega não tava aceitando o diagnóstico, se agravasse o quadro da paciente dele, ele ia ser obrigado a fazer uma denúncia no Conselho Regional de Medicina, porque ele tava sendo negligente e ignorante". (Clarice, família Soneto) 
O trecho evidencia a responsabilização do médico pela saúde de Cecília, já que, mesmo estando longe, coloca-se à disposição para responder a necessidade da família, dando-lhes o número de seu telefone particular para que pudesse ser acionado quando necessário. Diante da possibilidade do quadro de $A V E$, o médico atende prontamente à necessidade da família, tomando para si a responsabilidade pelo cuidado, agindo em prol da menina ao gerenciar o atendimento para Cecília, inclusive, se dispondo a denunciar o outro profissional caso ele não cumprisse o que the cabia frente à gravidade da situação.

Neste caso, a relação entre o médico e a família se aproxima da noção de responsabilização, caracterizada como tão próxima e tão clara que o profissional deve se sentir responsável pela vida e morte da pessoa que vivencia o adoecimento, sensibilizando-se com todo o seu sofrimento9.

Além disso, a especificidade da atenção requerida no caso de um agravo peculiar, como a anemia falciforme, faz com que o acompanhamento se dê, preferencialmente, em uma unidade de referência especializada, conferindo um grau acentuado de importância na gestão dos casos; somado a isso, destacamos o tempo de relacionamento entre o médico e a pessoa acompanhada, que tende a se estender devido à própria situação de complexidade inerente ao agravo. Esses fatores contribuem para despertar o sentimento de "pertencimento", atribuindo, ao Centro de Hematologia, a referência de lugar de cuidado para a família, podendo ser esse um dos elementos que potencializaram o vínculo na situação da família Soneto.

$\mathrm{Na}$ experiência de André, acompanhado pelo médico então prefeito da cidade, Humberto, desde 2006, a relação de amizade entre eles, anterior à doença, contribuiu intensamente para que o profissional se responsabilizasse pela sua situação de saúde, garantindo um "canal de comunicação" mesmo quando o profissional se encontrava ausente.

Esse fato é percebido quando o médico orienta a secretária a telefonar para avisar André acerca do momento em que estaria na cidade para prestar assistência:

\footnotetext{
"Aí, após isso, comecei trabalhar na Prefeitura, né? Então, o prefeito era amigo da gente, o Doutor também né? [evidenciando que o prefeito também era o médico]. A gente falou com ele: 'Doutor Humberto tá me acontecendo assim, assim'. Ainda, ele falou pra mim: 'Olha, André: tal dia, eu não to lá, eu vou pra Cuiabá, mas cê deixa falado lá com a Clara, minha secretária, que o dia que eu for atender, eu te chamo'. Bão! Voltei a trabalhar normal, fui trabalhando. Quando foi na segunda-feira, a secretária dele me chamou: 'Oh! O Doutor Humberto disse que é pra você ir consultar que ele tá lá hoje, não foi pra Cuiabá não'. Então eu vou lá, né?". (André, família de André)
}

Consideramos que, nesse episódio, o médico foi quem acionou a relação, solicitando que André comparecesse ao consultório. Mesmo na ausência do profissional, há uma garantia de comunicação para que a pessoa adoecida não fique desamparada, ainda que momentaneamente não se possa oferecer uma resposta ao que está sendo por ela demandado, havendo o comprometimento da secretária em avisar acerca da disponibilidade do médico para atender André. Desse modo, percebemos que a responsabilização é permeada pelo compromisso mútuo, ou seja, da pessoa em procurar ajuda quando se faz preciso e, sobretudo, do profissional que se mobiliza para garantir, minimamente, um meio de conexão entre sua capacidade de resposta e a necessidade da pessoa.

O elemento que parece ter pesado para a responsabilização do profissional médico na história de André foi a presença do laço de amizade, preexistente à descoberta do agravo de saúde. Tal laço densificou a relação entre profissional e pessoa adoecida, pois, além do médico, estava presente o amigo, numa relação de proximidade única, não identificada nas demais histórias que compõem nossa análise. Essa relação próxima se mostrou tão forte que, no momento em que André precisava realizar uma colostomia e estava receoso em se submeter ao procedimento, o amigo médico foi até a sua casa para aconselhá-lo:

"Aí, o prefeito [se referindo ao médico], que tinha me consultado e me mandado pra lá [referência de tratamento ao câncer na cidade de Barretos], ficou sabendo que eu tava meio 
assim, pé meio atrás. Foi em casa, me deu uma força, falou: 'Olha, eu sou um médico, eu te aconselho. Vai! Porque se você não colocar hoje, amanhã ou depois, o tumor vai crescer, vai ter que colocar e nem pode [...] você vai ter que conviver com essas coisas'". (André, família de André)

Esse episódio nos chamou a atenção por demonstrar uma relação permeada pela afetividade construída a partir do laço de amizade, transcendendo a relação médico-paciente, e que se mostrou efetiva no tratamento de André. Percebemos uma postura reflexiva do profissional ao se reconhecer no amigo e se responsabilizar por sua situação; também, contribuiu para que André atribuísse um sentido novo à sua doença, reconhecendo sua gravidade e adquirindo certa confiança no tratamento que o amigo previa para sua situação.

Dentre os diversos tipos de laços que permeiam as relações humanas, está o laço de amizade, que é considerado forte por permitir, conforme sua permanência e vitalidade, a construção da confiança e compromisso mútuo ${ }^{10}$. A mesma autora afirma que tal laço, quando presente no sistema de saúde, pode proporcionar, à pessoa, a ânsia por um nível de cuidados superior ao padrão normalmente oferecido, e que laços fortes permitem acesso mais facilitado e de qualidade ao sistema de saúde, seja público ou privado.

Esse laço, quando estabelecido com um amigo médico, tende a proporcionar, à pessoa, uma sensação de despreocupação com assuntos relativos à saúde, ao mesmo tempo em que lhe inspira uma sensação de confiança em caso de problema ${ }^{10}$. Nesse sentido, podemos afirmar que o laço de amizade entre André e seu médico garante que o profissional se sinta comprometido e responsabilizado com seu estado de saúde, buscando meios, sem poupar esforços, para que possa lhe garantir o melhor cuidado.

Na situação da família Soneto, apesar de não haver esse laço de amizade anterior ao adoecimento dos filhos, percebemos um atendimento bem próximo do que poderia ser considerado integral, nos momentos em que a escuta, a atenção e a palavra de consolo se fizeram presentes, proporcionando, aos pais, a sensação de acolhimento, como narra Clarice:

“[...] Nós fizemos essa avaliação dela [refere-se ao exame de Doppler] por Deus, porque ela [a filha] não foi encaminhada pra ser avaliada por ela [médica que realizou o exame], mas como ela mesmo realizou, fez o Doppler e foi conversando, aí, no final, ela sentou, conversou comigo, me mostrou. Então assim, foi uma atenção diferenciada que ela me deu [ênfase] [...] Mas assim, ela conversou. Aquele dia que ela terminou o exame das crianças, ela sentou, ela me deu uma atenção, conversou comigo, explicou, me orientou muita coisa e me tranquilizou [ênfase]. (Clarice, família Soneto)

Elementos como a comunicação próxima, a palavra de consolo e a postura de se importar com o sofrimento do outro parecem contribuir para o estabelecimento do vínculo em saúde; se tais elementos guardam relação com o modo como o serviço de saúde se organiza para oferecer assistência às pessoas, muito mais direta é sua dependência para com a maneira como o profissional se posiciona em relação à situação vivenciada pela pessoa e sua família. É importante que ele seja capaz de desenvolver empatia pela pessoa adoecida, oferecendo uma atenção mais solidária, voltada aos que dele necessitam.

Tais elementos viabilizam o acolhimento da pessoa e família, sendo de fundamental importância na tecitura de uma relação vinculante pelo profissional. Corroboramos que o acolhimento é o ato ou efeito de acolher, amparar, e se expressa de variadas formas por meio de uma ação de aproximação, um "estar com" e um "estar perto de", uma atitude de inclusão da pessoa adoecida"1.

A sensação de acolhimento por parte da família Soneto se mostrou presente na relação com os médicos, com a equipe de enfermagem e de nutrição do Centro de Hematologia que acompanhava os adolescentes. A descrição seguinte destaca o reconhecimento, pela família, das pessoas com as quais "eles podiam contar": 


\begin{abstract}
"Num período mais difícil, nós contamos com um grupo que foi muito importante na nossa vida no Centro de Hematologia, que era uma enfermeira, que ficava na transfusão. Pra nós, o fato de você vê a bolsa lá pendurada e o seu filho tomando sangue, enquanto transfundia, eu tava chorando. Se a transfusão durasse duas horas, eu passava duas horas chorando! Cada gota de sangue era lágrima minha [risos], que tava ali. Então, nós contamos com esse grupo, que era a enfermeira, a Rita, que hoje nem tá mais lá, mas nunca esqueci o nome dela. [...] Foi as técnicas, parte delas ainda tão lá, outra parte aposentaram, e tinha doutor Daniel que me ajudou muito [...]. Mas o que fez foi o grupo de enfermagem e o médico! Eles fizeram uma diferença muito grande, e a nutricionista". (Clarice, família Soneto)
\end{abstract}

Parece-nos que esses profissionais foram capazes de acolher as necessidades da família em momentos de dificuldade, oferecendo uma atenção longitudinal, o que fez com que o Centro de Hematologia se tornasse um lugar de referência e pertencimento para eles ao longo do tempo. Dessa forma, percebemos que esse serviço se configurou como lócus de referência para o cuidado à saúde, funcionando como uma estação organizadora da atenção, visto que não só prestava os cuidados que lhes são próprios, mas também construía pontes com outros serviços e profissionais sempre que necessário ${ }^{12}$.

Cabe pontuar que o fato de os centros de especialidades apresentarem baixa rotatividade de seus profissionais, mantendo-os por um período de tempo mais longo, permite o acompanhamento prolongado das pessoas adoecidas que neles são atendidas, o que parece contribuir para o fortalecimento das relações, além do oferecimento de uma atenção longitudinal. Entretanto, a postura de cada profissional que neles atua ainda constitui fator crucial para a manutenção dessa relação, pois seria de pouca valia manter num serviço um profissional que não fosse capaz de criar empatia com a situação de adoecimento vivenciada pelas famílias.

Assim, neste estudo, a atenção ofertada de modo longitudinal às pessoas, ou apenas a permanência de um mesmo profissional no cuidado a elas, parece se configurar como elemento importante na tecitura do vínculo. Em contraponto, e reforçando essa inferência, na situação de André, a alta rotatividade dos médicos que o acompanharam em um centro de referência para tratamento de câncer no estado de São Paulo foi um fator dificultador nessa tecitura:

“Eu não sei dizer quantos médicos eu passei lá. Acho que eu passei uns cem. Cada dois dia passava um, né? Esse um foi que me acompanhô na parte da cirurgia [...] Quem fez cirurgia foi um. Aí, e antes de eu saí de alta, já teve doutor que me acompanhou. Depois, já me jogaram pra outro, e vai... Acho que a cada dia um, só pode!". (André, família de André)

Entendemos que a rotatividade de profissionais no serviço de saúde, sobretudo no atendimento a uma mesma pessoa adoecida ao longo do tempo, pode acarretar certa instabilidade nas relações, a depender de como cada profissional conduzirá o tratamento da pessoa que está em acompanhamento. Além disso, a mudança constante dos profissionais que acompanham a pessoa pode causar uma percepção de se estar "jogado" de um para outro profissional, conforme expressa André, sendo que, também nas suas palavras, os profissionais apenas "passavam" por ele, não se tornando responsáveis ou comprometidos com o acompanhamento da sua situação.

Em contrapartida, cabe destacar que apenas a permanência de um mesmo profissional ao longo do tempo não é condição única para o oferecimento de uma atenção longitudinal, posto que a essência da longitudinalidade se conforma em uma relação pessoal, de longa duração, entre profissional, pessoa adoecida e sua família, e que independe da presença de uma doença ${ }^{12}$. O profissional deve reconhecer a pessoa, mas, também, permitir ser reconhecido por ela, conferindo, assim, sentido à relação estabelecida ${ }^{13}$. É válido afirmar que essa relação só pode ser construída ao longo do tempo; porém, para que ela se efetive, são necessários inúmeros elementos que se inter-relacionam na continuidade da assistência.

Na experiência de Dona Mocinha, acompanhada pelo mesmo médico há mais de vinte anos, percebemos que a relação mantida se caracterizou por uma afetividade vinculante, pautada no 
"apego" da idosa e sua família ao profissional, por trazer algum grau de resposta às suas necessidades e, sobretudo, por tratá-las com cordialidade.

“Ele é muito atencioso. [...] Ele num tem pressa de atender a gente. [...] Cê chega lá, ele te escuta, tudo o que for necessário, né? [...] Achamos ele muito legal, gosto muito de tratá com ele". (Dona Mocinha, família de Dona Mocinha)

A relação que a idosa estabelece com o médico é permeada pela confiança que ela e sua família têm nesse profissional, pois ele atende, também, a outros entes da família:

"A minha irmã, mais criança do que eu, ela teve probrema de derrame [...] teve cinco vezes esse probrema de derrame. Então, ela tratava com ele, sabe? Com Dotô Luiz. Aí então, ela foi e falô assim: 'Olha, o médico, Dotô Luiz, ele é muito bom! Muito atencioso, tudinho, né?!'" (Dona Mocinha, família de Dona Mocinha)

Entendemos que a tecitura de uma relação respeitosa e cordial por parte do profissional de saúde contribui, em grande medida, para que as pessoas e suas famílias se vinculem - e permaneçam vinculadas - a ele. O médico atencioso da irmã de Dona Mocinha tornou-se também seu médico atencioso. Entretanto, para que o vínculo em saúde seja efetivo, outros elementos são fundamentais na relação entre profissional, pessoa adoecida e família.

Observamos que a iniciativa de busca e manutenção dessa relação se dava por parte da idosa e sua família, e não o contrário, visto que, em nenhum momento nas narrativas, o médico ou outro profissional da clínica estabeleceram qualquer tipo de contato que não fosse atender estritamente ao que foi demandado.

Assim, entendemos que o vínculo em saúde deve se caracterizar por trocas solidárias e comprometidas com o cuidado à saúde ${ }^{14}$, pois não depende apenas da atitude da pessoa adoecida ao buscar o profissional para potencializar a efetivação de seus cuidados, posto que os profissionais devem estar implicados nesse processo, mobilizando saberes e ações que possam atender às necessidades das pessoas da melhor maneira possível. Dessa forma, corroboramos que a direção da tecitura do vínculo com as pessoas que necessitam de cuidado deve ser de iniciativa efetiva do profissional ${ }^{5}$. Não percebemos na experiência de Dona Mocinha e sua família essa atitude vinculante por parte do médico, visto que ela é quem nutre o vínculo afetivo com o profissional. Depreende-se que a afetividade vinculante de Dona Mocinha não seja suficiente para que o médico se mobilize, de modo mais efetivo, no acompanhamento à sua saúde.

A limitada responsabilização por parte do profissional, nesse caso, interfere na efetividade da assistência prestada à idosa, mas não na afetividade que a família nutre por ele. O tratamento cordial que o profissional oferece se mostra suficiente para que Dona Mocinha e sua família o reconheçam como seu "médico de confiança". Por sua vez, o médico parece não reconhecer a sua parcela de responsabilização com o cuidado integral da idosa e não empreende esforços para a tecitura do vínculo.

Cabe destacar que o adoecimento crônico é por nós considerado um estado mais ou menos prolongado na vida das pessoas; assim, a longitudinalidade da assistência torna-se imprescindível, no sentido de que o profissional se faça presente na relação, se colocando em prontidão para o cuidado, atitude que contribui para o sentimento de pertencimento e acolhimento das pessoas e suas famílias.

Nas três histórias abordadas neste estudo, apesar de se tratarem de pessoas adoecidas e famílias que necessitavam de acompanhamento próximo, a unidade básica da Estratégia Saúde da Família (ESF) não se mostrou capaz de tecer um vínculo efetivo com elas. Sabemos que, nessa relação, pesam diversos elementos que não estão plenamente sob a governabilidade da ESF. Entretanto, tomando a perspectiva privilegiada das pessoas e famílias participantes deste estudo, podemos apontar alguns fatores que atuaram como entraves na tecitura do vínculo por parte dos serviços de saúde.

$\mathrm{Na}$ história da família Soneto, observamos que o tempo de resposta às necessidades dos adolescentes foi um elemento dificultador na tecitura do vínculo com a ESF, como destaca Clarice: 
“Eu até tentei fazer, dois anos eu busquei o PSF. No primeiro ano, até que foi tranquilo; no segundo, eu já não conseguia receber assistência, e, no dia que foi feita a coleta [refere-se ao exame Papanicolau], demorô muito tempo [Ênfase] pro exame chegar. [...] Então, acaba causando uma demora, desgaste maior em você, a gente não tem tanto tempo pra ficar plantado esperando sabe lá Deus quando que vai chegar. E aí foi onde eu desisti deles". (Clarice, família Soneto)

Complementando a fala da mãe, Cecília (família Soneto) aponta: "O postinho médico é o menos importante! [ênfase, referindo-se ao PSF]. [...] Pra mim, não faz muita falta! Não sei pros outros".

A pouca agilidade também contribuiu para a não-tecitura de vínculo com a ESF, fazendo com que a família buscasse instituições que lhes pareceram mais eficientes e efetivas, fornecendo respostas mais rápidas, e que corresponderam às necessidades mais prontamente.

No caso de Dona Mocinha, observamos uma percepção da assistência oferecida na ESF pautada em uma atenção menos efetiva e destinada a pessoas menos favorecidas. Esse fator parece ter constituído um elemento contribuidor para o não-estabelecimento de vínculo, como evidencia a idosa no seguinte trecho:

“Eles [ESF] só pergunta assim, porque eu tenho o prano de saúde: 'tem prano de saúde?' eu tenho prano de saúde... aí eles descuida né, intão num adianta! [...] geralmente, é uma qualidade só [referindo-se à medicação prescrita na ESF]. 'É hipertenso? Você é hipertenso, você é?' O mesmo quase remédio que dá pra você, dá pra você". (Dona Mocinha, família de Dona Mocinha)

Ana, filha de Dona Mocinha, reforça: "[...] é! Acho que eles dão prioridade pra aquelas pessoas que não têm [plano de saúde]".

Percebemos que, quando a família de Dona Mocinha tem a possibilidade de não se submeter ao serviço público, assim o faz; de modo que acaba por estabelecer vínculo com os profissionais da rede privada e/ou conveniada. Portanto, embora a ESF tenha a longitudinalidade como intenção incorporada em sua política, é o médico particular de Dona Mocinha - mesmo sem a "continuidade" como sustentadora de sua assistência - que se apresenta a ela como capaz de lhe fornecer respostas mais efetivas às suas necessidades.

Tal como na história de André, a percepção aguda da qualidade da assistência prestada foi um elemento que também dificultou o estabelecimento de vínculo com a equipe da ESF:

“Fui no postinho umas duas vezes, falei com o médico lá [...]. O nosso médico é muito vagabundo, do postinho, é muito fraco, coitado! Aí ele pegou e fez lavagem. Eu fiquei olhando, né! Pegô, molhou uma água lá e lavou o meu ouvido. Aí, eu fui na farmácia um dia e falei pro farmacêutico: 'O Dê [apelido do farmacêutico], a gente faz limpeza no ouvido, assim com água?'. 'Não, é com soro!'. 'Nada, rapaz! O doutor lá fez limpeza no meu ouvido com água'. 'Não, é com soro!'. 'Mas ele fez limpeza no meu ouvido com água'. (André, família de André)

Em outro momento, André relata: “[...] Fui no postinho, né! Não sei o que aconteceu lá, porque na hora que tirei raio $X$, cheguei na sala de consulta, minha receita já tava feita, não sei se ela me viu no corredor [...] A receita do remédio já tava pronta".

Tais acontecimentos fizeram André desacreditar do compromisso do médico da ESF com o cuidado à sua saúde. Vale enfatizar que a postura médica pode levar as pessoas a duvidarem da competência do profissional para reconhecer suas necessidades de cuidado, bem como a não confiarem em suas condutas, fragilizando ainda mais a relação e o vínculo com o profissional e com o serviço.

Cada pessoa traz consigo uma cesta de necessidades quando procura um serviço de saúde. Logo, cabe ao profissional identificá-las e desenvolver o cuidado de maneira correspondente a elas ${ }^{15}$. Nesse sentido, acreditamos que a resposta efetiva ao que está sendo demandado pode ser um elemento que potencializa a tecitura do vínculo em saúde. 


\title{
Considerações finais
}

O vínculo se estabelece num movimento contínuo de relações afetivas e efetivas, sendo necessário um esforço por parte do profissional para intensificar relações vinculantes às pessoas e suas famílias. Espera-se uma postura proativa do profissional em se responsabilizar pela situação de adoecimento, pautando suas práticas na qualidade e no oferecimento de respostas adequadas e efetivas às necessidades da pessoa e família. Tais características da relação entre profissional, pessoa adoecida e família são, simultaneamente, causa e consequência da responsabilização profissional e da garantia da longitudinalidade do cuidado - elementos constituidores da tecitura do vínculo em saúde.

Apreendemos que o acompanhamento longitudinal viabilizou o desenvolvimento de uma relação de proximidade, que, por sua vez, possibilitou o reconhecimento precoce das necessidades da pessoa adoecida, promovido pelo interesse e responsabilização do profissional, que foi além de prestar atendimento quando acionado pela família, colocando-se em posição de prontidão para o cuidado quando e onde ele fosse necessário.

A tecitura do vínculo em saúde esteve relacionada às características do profissional, no sentido de responsabilizar-se e reconhecer necessidades mais ampliadas e integrais; e, também, ao tipo e tempo de relação existente. Portanto, entendemos que a garantia da longitudinalidade no cuidado possa ser um modo eficaz de se constituir vínculo efetivo entre o profissional e a pessoa adoecida e família. Ao mesmo tempo, o vínculo constitui um elemento potencializador da capacidade resolutiva dos serviços, garantindo a continuidade das ações de saúde e a longitudinalidade do cuidado, atendendo às expectativas das pessoas e famílias. Assim, temos a constituição do círculo virtuoso que apresentamos, imageticamente, no diagrama representativo dos elementos intrínsecos à tecitura do vínculo na relação entre profissional, pessoa adoecida e família.

\author{
Colaboradores \\ Juliana de Lima Soares participou da concepção do estudo, recolha e análise do material \\ empírico, redação, formatação e revisão final do texto. Laura Filomena Santos de Araújo \\ e Roseney Bellato participaram da concepção do estudo, análise do material empírico, \\ redação, formatação e revisão final do texto. Elen Petean participou da análise do material \\ empírico, redação, formatação e revisão final do texto.
}

\section{Referências}

1. Dolina JV, Bellato R, Araújo LFS. O adoecer e morrer de mulher jovem com câncer de mama. Cienc Saude Colet. 2013; 18(9):2671-80.

2. Mendes EV. O cuidado das condições crônicas na atenção primária à saúde: o imperativo da consolidação da estratégia da saúde da família. Brasília (DF): Organização Pan-Americana da Saúde; 2012.

3. Mendonça FAC, Sampaio LRL, Linard AG, Silva RM, Sampaio LL. Acolhimento e vínculo na consulta ginecológica: concepção de enfermeiras. Rev Rene. 2011; 12(1):57-64. 
4. Ministério da Saúde (BR). Secretaria de Atenção à Saúde. Política Nacional de Atenção Básica. Brasília (DF): MS; 2012.

5. Soares JL, Araújo LFS, Bellato R, Correa GHLST. Considerations about the health tie in the trajectory of search for elderly and the family care. J Res Fundam Care. 2013; 5(4):583-90.

6. Minayo MCS. O desafio do conhecimento. Pesquisa qualitativa em saúde. 12a ed. São Paulo: Hucitec; 2010.

7. Araújo LFS, Dolina JV, Petean E, Musquim CA, Bellato R, Lucietto GC. Diário de pesquisa e suas potencialidades em pesquisa qualitativa. Rev Bras Pesqui Saude 2013; 15(3):53-61.

8. Bandeira D, Sejanes T. Desvio e regra: linguagem do desenho. O Mosaico/FAP [internet]. 2009 [acesso 2013 Ago 19]; 1. Disponível em: http://www.fap.pr.gov.br/ arquivos/File/Arquivos2009/Pesquisa/Omosaico/02_artigo_Denise_thalita_aluna_sem_ Abstract.pdf

9. Merhy EE. Em busca da qualidade dos serviços de saúde: o serviço de porta aberta para a saúde e o modelo tecno-assistencial em defesa da vida. In: Cecílio LCO, organizador. Inventando a mudança na saúde. São Paulo: Hucitec; 2006. p. 17-160.

10. Portugal S. Dádiva, família e redes sociais. In: Portugal S, Martins $\mathrm{PH}$, organizadores. Cidadania, políticas públicas e redes sociais. Coimbra: Universidade de Coimbra; 2011. p. 39-53.

11. Ministério da Saúde (BR). Secretaria de Atenção à Saúde, Núcleo Técnico da Política Nacional de Humanização. Acolhimento nas práticas de produção de saúde. 2a ed. Brasília (DF): MS; 2008.

12. Starfield B. Atenção Primária - equilíbrio entre necessidades de saúde, serviços e tecnologia. Brasília (DF): Unesco, Ministério da Saúde; 2002.

13. Honneth A. Luta por reconhecimento: a gramática moral dos conflitos sociais. 34a ed. São Paulo: Editora 34; 2003.

14. Ministério da Saúde (BR). Secretaria-Executiva Núcleo Técnico da Política Nacional de Humanização. HumanizaSUS - Política Nacional de Humanização: a humanização como eixo norteador das práticas de atenção e gestão em todas as instâncias do SUS. Brasília (DF): MS; 2004.

15. Cecílio LCO. As necessidades de saúde como conceito estruturante na luta pela integralidade e equidade na atenção em saúde. In: Pinheiro R, Mattos RA, organizadores. Os sentidos da integralidade na atenção e no cuidado à saúde. 8 a ed. Rio de Janeiro: Abrasco; 2009. p. 117-30. 
Soares JL, Araújo LFS, Bellato R, Petean E. Urdimbre del vínculo de salud en la situaciones familiares de enfermedad crónica. Interface (Botucatu). 2016; 20(59):929-40.

Nuestro objetivo fue el de comprender el urdimbre del vínculo en la relación entre profesional, persona enferma y familia en situación crónica de enfermedad. Este estudio es de tipo cualitativo y fue efectuado a partir de una consulta al acervo de la base de datos de la investigación matricial, rescatando tres situaciones de enfermedad crónica. La relación mantenida por Doña Mocinha con su médico se caracterizó por el vinculo afectivo unidireccional. En la familia Soneto, la relación entre los adolescentes y el médico estaba basada en la reciprocidad y responsabilización profesional, constituyendo un vínculo de tipo bidireccional. En lo que respecta a la familia de André, el seguimiento médico contaba con un lazo de amistad, contribuyendo a la actuación proactiva del profesional en la atención. Las personas y familias estudiadas no establecieron vínculo con las Unidades Básicas de Salud, a pesar de vivir en áreas cubiertas por la Estrategia Salud de la Familia.

Palabras clave: Familia. Relaciones profesional-familia. Enfermedades crónicas. 